This article is licensed under the Creative Commons Attribution-NonCommercial 4.0 International License (CC BY-NC) (http://www.karger.com/Services/OpenAccessLicense). Usage and distribution for commercial purposes requires written permission.

\title{
Intrascleral Fixation of an Intraocular Lens through the Pars Plana Prevents Corneal Endothelial Damage
}

\author{
Naomi Miyamoto Momoko Yamakawa Masayuki Akimoto \\ Department of Ophthalmology, Osaka Red Cross Hospital, Osaka, Japan
}

\section{Keywords}

Intraocular lens · Corneal endothelial damage · Aphakia

\begin{abstract}
We report two cases of aphakia in whom an intraocular lens (IOL) was intrasclerally fixated through the pars plana to minimize further corneal endothelial damage. A modified lock-andlead technique was used. A sclerotomy and scleral incision were made $2.5 \mathrm{~mm}$ from the limbus. A 24-G catheter needle was used for penetration of the leading haptic, and two ultrathin 30-G needles were used to bury the ends of the haptics. The scleral incision was sutured with 8-0 nylon. Corneal endothelial cells were preserved after surgery. Neither intra- nor postoperative complications were observed. Intrascleral fixation of an IOL through the pars plana effectively minimizes further damage to corneal endothelial cells in select cases.
\end{abstract}

\footnotetext{
(C) 2019 The Author(s)

Published by S. Karger AG, Base
} 


\section{Case Reports in Ophthalmology}

Case Rep Ophthalmol 2019;10:53-60

DOI: $10.1159 / 000496534$

(c) 2019 The Author(s). Published by S. Karger AG, Base www.karger.com/cop

Miyamoto et al.: Intrascleral Fixation of IOL through Pars Plana

Introduction

Intrascleral intraocular lens (IOL) fixation is a standard technique for secondary implantation of IOLs in eyes without or with insufficient capsular support. Numerous variations of this technique have been reported [1-8]. Most procedures create a corneoscleral or corneal incision and require the placement of an IOL on the iris following some intracameral manipulations. Therefore, intrascleral IOL fixation must be performed with utmost care to prevent further damage to the diminished corneal endothelial cells. Corneal endothelial transplantation has recently been developed $[9,10]$; however, if possible, secondary IOL implantation procedures should be avoided requiring corneal transplantation. Therefore, we proposed that corneal endothelial cells could be preserved by performing all intraocular manipulations posterior to the iris through a scleral incision at the pars plana, thereby avoiding the cornea. Here, we report the successful preservation of corneal endothelial cells using this method in two cases.

\section{Case Report}

Intrascleral fixation of the IOL in each case was performed using our previously reported modified lock-and-lead technique [7, 8]. Briefly, an infusion trocar cannula was placed through the pars plana $3.5 \mathrm{~mm}$ from the limbus. The anterior vitreous was thoroughly removed. Under perfusion, a sclerotomy was made $2.5 \mathrm{~mm}$ from the limbus at the 5 o'clock position using a 20-G microvitreoretinal knife (Fig. 1A). Using a slit knife, a 3-mm scleral incision was made parallel to and $2.5 \mathrm{~mm}$ from the limbus opposite to the first sclerotomy site (Fig. 1B).

After the IOL was loaded into the injector, the catheter needle was inserted through the sclerotomy and penetrated through the 3-mm scleral incision (Fig. 1C). A modified guidance needle, which mimics a catheter needle, is used to fix IOL haptics between the external tube and the internal needle. The plunger of the injector was advanced until the leading haptic was released. The leading haptic was fixated between the external tube and the internal needle of the catheter needle outside of the scleral incision. Simultaneously, the catheter needle was pulled until the leading haptic exited the sclerotomy site, and the IOL was inserted into the eye through the 3-mm scleral incision (Fig. 1D). The catheter needle was loosened to release the leading haptic external to the sclerotomy site, while the trailing haptic remained external to the 3-mm scleral incision (Fig. 1E). Two 30-G ultrathin needles were prepared and used to bury the leading haptic in the scleral tunnel (Fig. 1F). The trailing haptic was buried in the scleral tunnel through the edge of the 3-mm scleral incision using two 30-G needles (Fig. 1G). The IOL centering and alignment were adjusted into position, and the scleral incision was closed using 8-0 nylon suture (Fig. $1 \mathrm{H}$ ). The perfusion was stopped, and the conjunctival wound was sutured using 8-0 Vicryl. A summarization of the procedure is shown in online supplementary video 1 (see www.karger.com/doi/10.1159/000496534 for all online suppl. material). 


\section{Case Reports in Ophthalmology}

\section{Results}

We performed this surgical procedure in two cases. A summary of the patients is shown in Table 1. Postoperative slit-lamp photographs and anterior segment optical coherence tomography are shown in Figure 2. No complications were observed during surgery or in the early postoperative phase. In both cases, we successfully preserved the corneal endothelial cells. However, the postoperative best corrected visual acuity was decreased in one case, partly due to superficial keratoconjunctivitis and mild dementia.

\section{Discussion}

In these two cases, we successfully performed intrascleral fixation of an IOL while preserving the corneal endothelial cells. Eom et al. [11] compared combined phacovitrectomy to pars plana vitrectomy with fragmentation and found that the latter method resulted in less endothelial damage. It is logical that procedural manipulations should be performed distant to the endothelial cells to prevent endothelial damage.

A 3-mm scleral incision was needed to insert the IOL through the pars plana. This is unusual; however, it is often required for the removal of intraocular foreign bodies. Although the incision is uncommon, our method has several advantages. Insertion of the trailing haptic into the scleral tunnel is facilitated by the highly flexible, 3-mm scleral incision. Therefore, we could easily determine the direction of the scleral tunnel and align the IOL. Less postoperative intraocular hemorrhage occurs from the pars plana than from the ciliary groove, the usual site for IOL scleral fixation. Since the IOL is positioned away from the iris plane, postoperative iris capture is avoided. Serious complications, such as postoperative hypotony, retinal detachment, and haptic scleral erosions, were not observed in either case.

We used to use the same IOL power for this procedure as that employed for an in-the-bag fixation through a sclerotomy $1.5 \mathrm{~mm}$ from the limbus. In the cases reported here, we selected an IOL with a refractive power $1 \mathrm{dpt}$ higher than that used in our previous procedures, because the IOL was fixed $2.5 \mathrm{~mm}$ from the limbus, posterior to our standard method. The postoperative refraction was as expected.

This report includes only two cases and is limited in scope. Therefore, further studies in additional patients are required to determine the effects of this technique on lens power selection. However, we believe this technique minimizes corneal endothelial cell damage during IOL intrascleral fixation in select cases.

\section{Statement of Ethics}

The authors have no ethical conflicts to disclose. 


\section{Disclosure Statement}

Dr. Masayuki Akimoto is a consultant for Kowa Co., Ltd., Nagoya, Japan. The other authors have no financial support to disclose.

\section{Author Contributions}

N.M. and M.Y. interpreted data. N.M. and M.A. wrote the paper. M.A. performed surgery and supervised it.

\section{References}

1 Gabor SG, Pavlidis MM. Sutureless intrascleral posterior chamber intraocular lens fixation. J Cataract Refract Surg. 2007 Nov;33(11):1851-4.

2 Agarwal A, Kumar DA, Jacob S, Baid C, Agarwal A, Srinivasan S. Fibrin glue-assisted sutureless posterior chamber intraocular lens implantation in eyes with deficient posterior capsules. J Cataract Refract Surg. 2008 Sep;34(9):1433-8.

3 Rodríguez-Agirretxe I, Acera-Osa A, Ubeda-Erviti M. Needle-guided intrascleral fixation of posterior chamber intraocular lens for aphakia correction. J Cataract Refract Surg. 2009 Dec;35(12):2051-3.

4 Yamane S, Inoue M, Arakawa A, Kadonosono K. Sutureless 27-gauge needle-guided intrascleral intraocular lens implantation with lamellar scleral dissection. Ophthalmology. 2014 Jan;121(1):61-6.

5 Ohta T, Toshida H, Murakami A. Simplified and safe method of sutureless intrascleral posterior chamber intraocular lens fixation: $y$-fixation technique. J Cataract Refract Surg. 2014 Jan;40(1):2-7.

6 Yamane S, Sato S, Maruyama-Inoue M, Kadonosono K. Flanged intrascleral intraocular lens fixation with double-needle technique. Ophthalmology. 2017 Aug;124(8):1136-42.

7 Akimoto M, Taguchi $\mathrm{H}$, Takahashi $\mathrm{T}$. Using catheter needles to deliver an intraocular lens for intrascleral fixation. J Cataract Refract Surg. 2014 Feb;40(2):179-83.

8 Akimoto M, Taguchi H, Takayama K, Nakagawa S, Hiroi K. Intrascleral fixation technique using catheter needles and 30-gauge ultrathin needles: lock-and-lead technique. J Cataract Refract Surg. 2015 Feb;41(2):257-61.

9 Ang M, Wilkins MR, Mehta JS, Tan D. Descemet membrane endothelial keratoplasty. Br J Ophthalmol. 2016 Jan;100(1):15-21.

10 Tong CM, Baydoun L, Melles GR. Descemet membrane endothelial keratoplasty and refractive surgery. Curr Opin Ophthalmol. 2017 Jul;28(4):316-25.

11 Eom Y, Kim SW, Ahn J, Kim JT, Huh K. Comparison of cornea endothelial cell counts after combined phacovitrectomy versus pars plana vitrectomy with fragmentation. Graefes Arch Clin Exp Ophthalmol. 2013 Sep;251(9):2187-93.

Presented at the 41st Annual Meeting of the Japanese Society of Ophthalmic Surgeons, Kyoto, Japan, January 2018 


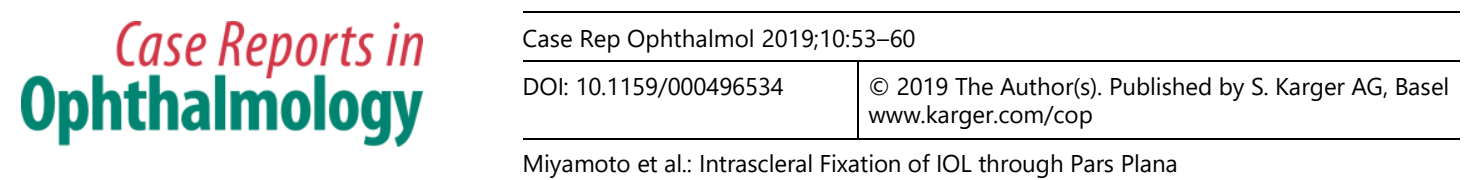
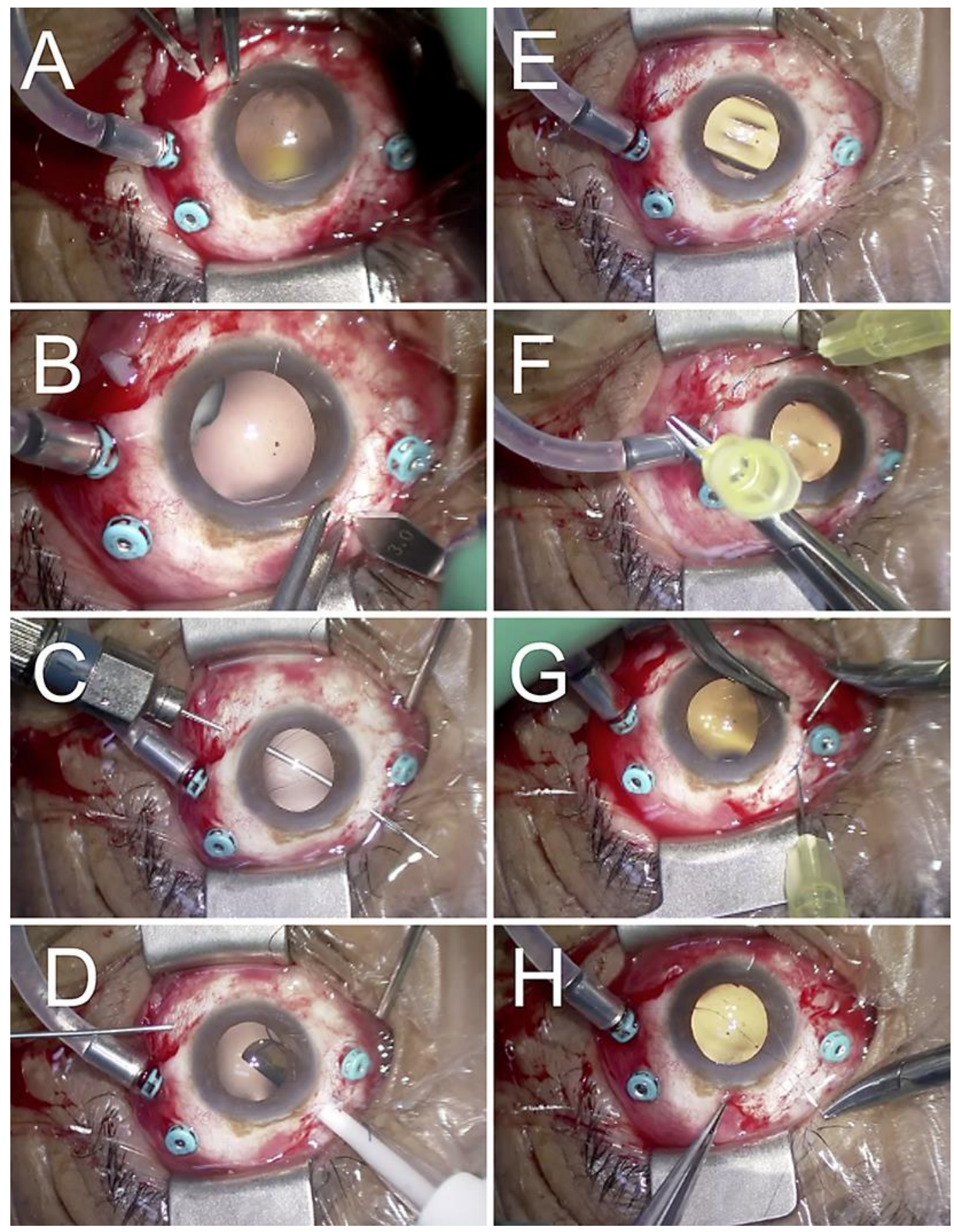

KARGER 
Miyamoto et al.: Intrascleral Fixation of IOL through Pars Plana

Fig. 1. Summarization of the surgical procedure for intrascleral IOL fixation through the pars plana. A A sclerotomy is made $2.5 \mathrm{~mm}$ from the limbus at the 5 o'clock position using a 20-G microvitreoretinal knife. B A 3-mm scleral incision is made parallel to and $2.5 \mathrm{~mm}$ from the limbus opposite to the first sclerotomy site using a slit knife. $\mathbf{C}$ The guidance needle is inserted through the sclerotomy and penetrated through the $3-\mathrm{mm}$ scleral incision. $\mathbf{D}$ The leading haptic is fixated between the external tube and the internal needle of the guidance needle outside the scleral incision. The guidance needle is pulled, and the IOL is inserted into the eye through the $3-\mathrm{mm}$ scleral incision simultaneously. $\mathbf{E}$ The guidance needle is pulled until the leading haptic exits the sclerotomy site. The guidance needle is loosened to release the leading haptic external to the sclerotomy. $\mathbf{F}$ The leading haptic is buried in the scleral tunnel using two 30-G needles. G The trailing haptic remains external to the $3-\mathrm{mm}$ scleral incision and is buried in the scleral tunnel through the edge of the incision using two 30-G needles. $\mathbf{H}$ After the scleral incision is closed with 8-0 nylon suture, the conjunctival wound is sutured with 8-0 Vicryl. 


\section{Case Reports in Ophthalmology}
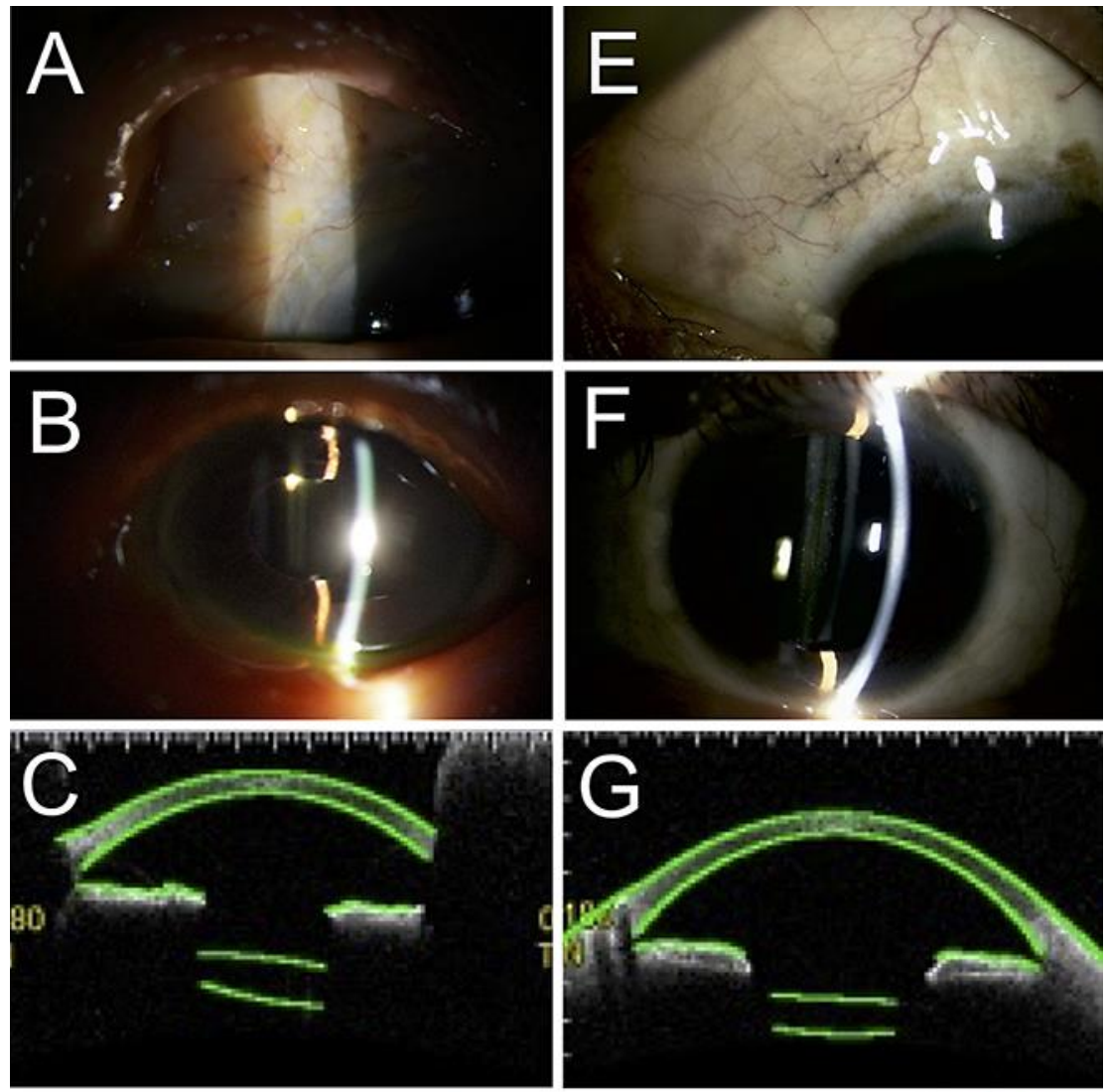

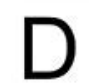

\section{Corneal aberration}

\section{Whole eye} aberration

Internal aberration
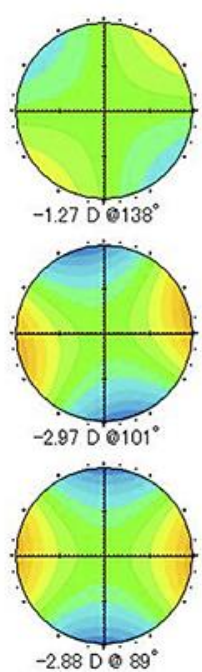

$\mathrm{H}$

Corneal aberration

Whole eye aberration

Internal aberration
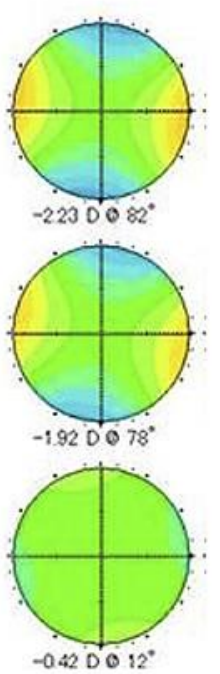

Fig. 2. Case 1 (A-D) and case $2(\mathbf{E}-\mathbf{H})$ are shown at 6 months postoperatively. There are no haptic scleral erosions. A, E The surgical incision was closed. B, F A slit-lamp photo showing the IOL correctly aligned and centered behind the iris. C, G Anterior segment optical coherence tomography confirming the IOL centration and alignment are positioned correctly. D, H Postoperative wavefront analysis detecting low internal and whole eye astigmatic aberrations, indicating the IOL tilt is within acceptable range. 


\section{Case Reports in Ophthalmology}

Table 1. Patient characteristics

\begin{tabular}{|c|c|c|c|c|c|c|c|c|}
\hline Case & $\begin{array}{l}\text { Age, } \\
\text { years }\end{array}$ & $\begin{array}{l}\text { Latera- } \\
\text { lity }\end{array}$ & $\begin{array}{l}\text { Past surgical } \\
\text { history }\end{array}$ & $\begin{array}{l}\text { Preoperative } \\
\text { lens status }\end{array}$ & $\begin{array}{l}\text { Preoperative cor- } \\
\text { neal endothelial } \\
\text { cell density }\end{array}$ & $\begin{array}{l}\text { Postoperative } \\
\text { corneal endothe- } \\
\text { lial cell density }\end{array}$ & $\begin{array}{l}\text { Preoperative } \\
\text { BCVA }\end{array}$ & $\begin{array}{l}\text { Postoperative } \\
\text { BCVA }\end{array}$ \\
\hline 1 & 89 & left & $\begin{array}{l}\text { PEA anterior } \\
\text { vitrectomy }\end{array}$ & aphakia & $1,370 / \mathrm{mm}^{2}$ & $1,294 / \mathrm{mm}^{2}$ & $20 / 25$ & $20 / 40$ \\
\hline 2 & 53 & left & $\begin{array}{l}\text { PEA IOL inser- } \\
\text { tion }\end{array}$ & $\begin{array}{l}\text { a dislocated lens } \\
\text { with a Soemmer- } \\
\text { ing ring }\end{array}$ & $1,164 / \mathrm{mm}^{2}$ & $1,130 / \mathrm{mm}^{2}$ & $20 / 16$ & $20 / 12.5$ \\
\hline
\end{tabular}

BCVA, best corrected visual acuity; PEA, phacoemulsification and aspiration. 